\title{
Risk prioritization based on the combination of FMEA and dual hesitant fuzzy sets method
}

\author{
Lucas Daniel Del Rosso Calache ${ }^{a^{*}}$ (D), Lucas Gabriel Zanon ${ }^{\mathrm{a}}$ (D), Rafael Ferro Munhoz Arantes ${ }^{\mathrm{a}}$ (D), \\ Lauro Osirob ${ }^{\mathrm{b}}$ (D), Luiz Cesar Ribeiro Carpinettia \\ aUniversidade de São Paulo, São Carlos, SP, Brasil

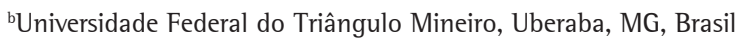 \\ *lucascalache@usp.br
}

\begin{abstract}
Paper aims: This paper proposes the combination of the quality tool FMEA (Failure Modes Effects and Analysis) with the DHFS (Dual Hesitant Fuzzy sets) technique to process judgements with hesitation and hence conduct the prioritization of failure modes considering a group decision making problem.

Originality: There are no studies that combine the FMEA tool with the DHFS technique.

Research method: Firstly, this paper presents a review of the current FMEA literature. Then, the group decision model is presented combining the FMEA and the DHFS. Finally, an illustrative example in the context of supplier failure modes is brought to guide future applications of the proposal.

Main findings: The paper presents a model that combines the FMEA tool with the DHFS. It allows considering different risk factors weights in a group decision process with experts from several areas. The model is also able to deal with the different types of hesitations present in the judgements.

Implications for theory and practice: The traditional FMEA does not deal with individual judgments of different decision makers. The new proposal can be easily applied in different contexts of potential failure modes analysis considering different types of hesitation in group decision making, such as medical and humanitarian.
\end{abstract}

Keywords

FMEA. Dual Hesitant Fuzzy Sets. Risk evaluation. Supplier failure modes. Group decision.

How to cite this article: Calache, L. D. D. R., Zanon, L. G., Arantes, R. F. M., Osiro, L., \& Carpinetti, L. C. R. (2021). Risk prioritization based on the combination of FMEA and dual hesitant fuzzy sets method. Production, 31, e20200081. https:// doi.org/10.1590/0103-6513.20200081.

Received: Aug. 6, 2020; Accepted: May 10, 2021.

\section{Introduction}

The quality management processes seek to cope with changes in an increasingly complex and dynamic environment while ensuring that organizations are able to deliver products and services that comply and satisfy their customers (Fonseca, 2015). The ISO 9000 series of international standards has become an important reference and a key management structure for all types of organizations around the world (Fonseca \& Domingues, 2017). The update of the 1SO 9001: 2015 standard presents a thinking based on risk management and process-based approaches, which highlights the growing emphasis on risk management within quality management programs (Sitnikov et al., 2017).

Failure Modes and Effects Analysis (FMEA) is one of the most well-known quality management tools used to deal with risk assessment in continuous improvement programs for products, processes, and services (Kumru \& Kumru, 2013). The literature presents a large number of studies that apply the FMEA in several problems, such as: applications to reduce medical errors (Li et al., 2017; Bonfant et al., 2010; Chiozza \& Ponzetti, 2009); 
development of new products (Lorenzi \& Ferreira, 2018; Lin et al., 2015; Chin et al., 2008); approaches for supplier selection problems (Arabsheybani et al., 2018; Foroozesh et al., 2018; Chen \& Wu, 2013), among others.

The traditional FMEA risk prioritization number (RPN) is based on the decision maker's judgment about the risk factors severity, occurrence, and detection. Although the FMEA technique is widely diffused, many studies present proposals for the improvement of the technique by adding more risk factors and/or incorporating weights on them (Fattahi \& Khalilzadeh, 2018; Chang, 2016; Liu et al., 2012). In addition, the evaluation of the risk factors is difficult to be precisely determined, since it involves imprecision that needs to be treated (Rahmatin et al., 2018; Liu et al., 2013, Liu et al., 2015a). In order to overcome this problem, some papers combine fuzzy techniques with the FMEA, such as: Fuzzy Cognitive Map (Rezaee et al., 2018), Fuzzy MOORA (Arabsheybani et al., 2018), Fuzzy Inference System (Geramian et al., 2017), Fuzzy VIKOR (Liu et al., 2015b), Technique for Order of Preference by Similarity to ldeal - Fuzzy TOPSIS (Song et al., 2013) and Analytic Hierarchy Process - Fuzzy AHP (Abdelgawad \& Fayek, 2010).

The literature presents the FMEA as an efficient tool that must be conducted as a group decision making problem, which involves the interrelationship between the departments of an organization (Liu et al., 2015c; Chin et al., 2009). However, most techniques do not deal with the group decision making process and do not allow decision makers to hesitate in their judgments. Hence, techniques based on the hesitant fuzzy representations (Zolfaghari \& Mousavi, 2018; Chang et al., 2018) and intuitionistic fuzzy (Tooranloo et al., 2018; Mirghafoori et al., 2018; Can, 2018) were proposed to consider group decision making in FMEA applications, however, each representation deals with hesitation in its own way (Calache, 2018). The Hesitant Fuzzy representations are used when there are doubts in the judgment, being able to activate one or more linguistic terms for the variable (Zhang et al., 2016). The Intuitionist Fuzzy representation is used to add a margin of hesitation in the definition of the fuzzy numbers that represent the linguistic terms (Nguyen, 2016). To explore the advantages of both representations Zhu et al. (2012) proposed the Dual Hesitant Fuzzy Sets (DHFS). The DHFS are more flexible than the existing fuzzy sets, which enables to deal with much more information in real world problems (Singh, 2017). Also, there are no studies that combine the FMEA tool with the DHFS technique.

Therefore, this paper presents a new model that combines the FMEA tool with the Dual Hesitant Fuzzy technique. The advantages of the proposed model over the FMEA proposals found in the literature are that it deals simultaneously with: different risk factor weights; individual judgments that represent the knowledge of experts from several different areas; it considers imprecision in the judgments through fuzzy set theory; it uses linguistic terms to represent the judgments of decision makers; it considers the hesitation from the linguistic terms parameterization and; it considers the hesitation in the judgments caused by the decision makers. The article is structured as follows: Section 2 presents the basic concepts of the traditional FMEA; Section 3 discusses the group decision making applications in FMEA. The Dual Hesitant Fuzzy Sets technique and the aggregation operator used are exhibited in Section 4. Section 5 presents the proposed model that integrates the FMEA application with the DHFS approach to deal with group decision making. An illustrative application is developed in Section 6 and, finally, Section 7 presents the conclusions and future works.

\section{FMEA}

FMEA is an analytical method of risk assessment that seeks to identify, prioritize, and determine the causes and effects associated with failure modes (Fattahi \& Khalilzadeh, 2018). Potential failure modes are defined as the way in which a component, a system, or a subsystem can potentially fail to achieve or deliver the functionality described for the item (Xu et al., 2002). FMEA is not only limited to failures, but includes errors in general, which are the inability to function in a certain way or to operate in an undesired way regardless of the cause (Jiang et al., 2017). In this way, the FMEA is presented as a powerful tool that has been applied in several industrial sectors (Liu et al., 2013), such as the aerospace sector (Yazdi et al., 2017; Chaudhuri et al., 2013), product development (Zhu et al., 2018; Chang, 2016), and several applications in healthcare (Liu et al., 2017; Wang et al., 2016).

The most important indicator used by the traditional FMEA is the Risk Priority Number (RPN), calculated according to the following equation: RPN $=0 \times \mathrm{S} \times \mathrm{D}$, where $\mathrm{O}, \mathrm{S}$ and $\mathrm{D}$ respectively represent the risk factors of Occurrence, Severity, and Detection (Geramian et al., 2017). These factors are evaluated by experts that give scores from 1 to 10 for each factor related to each risk analyzed, according to the example presented in Table 1. The results obtained by multiplying the risk factors are used to prioritize the analyzed risks (Liu et al., 2012).

Some literature review studies were performed to analyze applications of the FMEA tool: Liu et al. (2013) presents the main limitations that are being addressed by the new proposals of combinations of techniques with the FMEA; Kabir \& Papadopoulos (2018) present a review of the application of fuzzy representations with the 
Table 1. Typical rates for failure mode index.

\begin{tabular}{cccc}
\hline Rating & Occurrence & Severity & Detection \\
\hline 1 & Almost never & No severity & Certainty of detection \\
2 & Extremely Low & Extremely Low & Extremely high \\
3 & Very low & Very low & High \\
4 & How & Low & Average \\
5 & Moderately Low & Moderately Low & Moderately Low \\
6 & Average & Average & Low \\
7 & Moderately High & Moderately High & Very low \\
8 & High & High & Extremely Low \\
9 & Very High & Very High & Almost impossible \\
\hline
\end{tabular}

FMEA tool for safety and reliability engineering; $\mathrm{Ng}$ et al. (2017) reviews the integration of FMEA with other quality tools for problem solving; Sutrisno et al. (2013) carried out a survey of Improvement strategy in FMEA; Chrysostom \& Dwivedi (2013) raised the methodologies used in the FMEA and pointed the intuitionistic fuzzy as being the representation used to deal with the problem of group decision making. Despite the literature review work presented, no study has mapped the techniques used to deal with the problem of group decision making, which will be addressed in the next section.

\section{Group decision making in the FMEA}

As pointed out in the literature, the procedures for risk assessment and prioritization of failure modes by the FMEA tool can usually be considered as a multi criteria group decision making problem with the imprecision of information (Wang et al., 2018). In this way, the Fuzzy-Set-Based representations have been incorporated in several multi criteria decision-making techniques in order to overcome the limitations pointed out in the traditional FMEA method to deal with imprecise data (Hu et al., 2019; Huang et al., 2018; Liu et al. 2013).

Table 2 presents the articles that address the group decision making problem in the FMEA tool. It shows the proposal of each article and the factors considered in the problem scope. Therefore, it is possible to identify the advantages of the proposed model when compared with the other studies. The proposed combination of FMEA with the DHFS representation can cope with all aspects analyzed in Table 2, such as: the definition of different weights for the risk factor; collection of individual judgments in order to consider a holistic problem view; fuzzy logic is used to deal with imprecisions; the decision makers use linguistic terms to represent their judgments; the hesitation in the definition of the linguistic terms parameterization and the hesitation in the judgments of the decision makers are addressed by the DHFS representation.

The studies in Table 2 present a variety of techniques, representations of information and application contexts. With the exception of TOPSIS, all techniques were applied only once. In addition, it is possible to perceive a predominance of techniques that aggregate different judgments from different decision makers and few consensus approaches that involve the minimization of divergence among decision makers. Concerning the aggregation operators, the most commonly applied are those based on weighted average, for instance, Huang et al. (2017) use the weighted averaging operator of linguistic distribution assessments; Chai et al. (2016) apply the linguistic weighted average operator; Wang et al. (2016) use the intuitionistic fuzzy ordered weighted average operator; Tooranloo (2016) employ the intuitionistic fuzzy weighted average operator; Chaudhuri et al. (2013) implement the ordered weighted averaging operator.

Regarding the information representations, a great predominance of the linguistic variables based on the fuzzy set theory was observed. However, it was not found studies that deals with Dual-Hesitant Fuzzy sets in failure modes analysis.

\section{Dual hesitant fuzzy}

The fuzzy set theory initially proposed by Zadeh (1965) obtained wide acceptance in several fields of study, as well as in the risk management through the application of fuzzy FMEA. Many generalized forms of fuzzy sets have been proposed to deal with the imprecision of these problems such as: intuitionistic fuzzy (Tooranloo et al., 2018; Zhu et al., 2018); hesitant fuzzy (Chang et al., 2018; Soyer et al., 2016); type-2 fuzzy (Akyuz \& Celik, 2018; Bahrebar et al., 2018), among others. 
Table 2. FMEA articles and group decision making.

\begin{tabular}{|c|c|c|c|c|c|c|c|}
\hline Paper & Proposal & $\begin{array}{l}\text { Pondering } \\
\text { risk factors } \\
\text { weights }\end{array}$ & $\begin{array}{l}\text { Consider } \\
\text { individual } \\
\text { judgments }\end{array}$ & $\begin{array}{l}\text { Deals with } \\
\text { imprecision }\end{array}$ & $\begin{array}{l}\text { Use linguistic } \\
\text { terms for } \\
\text { judgments }\end{array}$ & $\begin{array}{l}\text { Hesitation in the } \\
\text { linguistic terms } \\
\text { parameterization }\end{array}$ & $\begin{array}{l}\text { Hesitation in } \\
\text { the judgment }\end{array}$ \\
\hline $\begin{array}{l}\text { Jenab \& Dhillon } \\
\text { (2005) }\end{array}$ & $\begin{array}{l}\text { Group-based failure } \\
\text { effects analysis. }\end{array}$ & & & $\checkmark$ & & & \\
\hline Chin et al. (2009) & $\begin{array}{l}\text { Failure mode and } \\
\text { effects analysis using a } \\
\text { group-based evidential } \\
\text { reasoning approach. }\end{array}$ & & $\checkmark$ & & & & \\
\hline $\begin{array}{l}\text { Zhang \& Chu } \\
\text { (2011) }\end{array}$ & $\begin{array}{l}\text { Fuzzy-RPNs-based } \\
\text { method integrating } \\
\text { weighted least square } \\
\text { method. }\end{array}$ & & $\checkmark$ & $\checkmark$ & $\checkmark$ & & \\
\hline $\begin{array}{l}\text { Chaudhuri et al. } \\
\text { (2013) }\end{array}$ & $\begin{array}{l}\text { A group decision } \\
\text { making approach using } \\
\text { numeric and linguistic } \\
\text { data. }\end{array}$ & & $\checkmark$ & $\checkmark$ & $\checkmark$ & & \\
\hline Ko (2013) & $\begin{array}{l}\text { 2-tuple linguistic } \\
\text { representational model } \\
\text { for constructing HOQ- } \\
\text { based failure modes and } \\
\text { effects analysis. }\end{array}$ & $\checkmark$ & & $\checkmark$ & $\checkmark$ & & \\
\hline $\begin{array}{l}\text { Helvacioglu \& } \\
\text { Ozen (2014) }\end{array}$ & $\begin{array}{l}\text { Integrates and apply the } \\
\text { Fuzzy TOPSIS technique } \\
\text { in the FMEA tool. }\end{array}$ & $\checkmark$ & $\checkmark$ & $\checkmark$ & $\checkmark$ & & \\
\hline Liu et al. (2014a) & $\begin{array}{l}\text { A new risk priority } \\
\text { model is proposed for } \\
\text { evaluating the risk of } \\
\text { failure modes based on } \\
\text { fuzzy set theory and } \\
\text { MULTIMOORA method. }\end{array}$ & $\checkmark$ & $\checkmark$ & $\checkmark$ & $\checkmark$ & & \\
\hline Liu et al. (2014b) & $\begin{array}{l}\text { Risk priority model } \\
\text { using interval 2-tuple } \\
\text { hybrid weighted } \\
\text { distance (ITHWD) } \\
\text { measure. }\end{array}$ & $\checkmark$ & $\checkmark$ & $\checkmark$ & $\checkmark$ & & \\
\hline Liu et al. (2014c) & $\begin{array}{l}\text { Risk assessment } \\
\text { methodology using } \\
\text { intuitionistic fuzzy } \\
\text { hybrid weighted } \\
\text { Euclidean distance } \\
\text { operator. }\end{array}$ & $\checkmark$ & $\checkmark$ & $\checkmark$ & $\checkmark$ & $\checkmark$ & \\
\hline Lolli et al. (2015) & $\begin{array}{l}\text { FlowSort-GDSS is } \\
\text { proposed to sort the } \\
\text { failure modes into } \\
\text { priority classes by } \\
\text { involving multiple } \\
\text { decision-makers. }\end{array}$ & $\checkmark$ & & $\checkmark$ & & & \\
\hline Liu et al. (2015c) & $\begin{array}{l}\text { FMEA approach } \\
\text { combining interval } \\
\text { 2-tuple linguistic } \\
\text { variables with gray } \\
\text { relational analysis. }\end{array}$ & $\checkmark$ & $\checkmark$ & $\checkmark$ & $\checkmark$ & & \\
\hline Chai et al. (2016) & $\begin{array}{l}\text { Interval type-2 fuzzy } \\
\text { sets applied with the } \\
\text { FMEA tool. }\end{array}$ & $\checkmark$ & & $\checkmark$ & $\checkmark$ & & \\
\hline $\begin{array}{l}\text { Wang et al. } \\
(2016)\end{array}$ & $\begin{array}{l}\text { Integrates COmplex } \\
\text { PRoportional } \\
\text { ASsessment (COPRAS) } \\
\text { and analytic network } \\
\text { process (ANP) method } \\
\text { and interval-valued } \\
\text { intuitionistic fuzzy } \\
\text { context. }\end{array}$ & $\checkmark$ & $\checkmark$ & $\checkmark$ & $\checkmark$ & $\checkmark$ & \\
\hline $\begin{array}{l}\text { Hajiagha et al. } \\
\text { (2016) }\end{array}$ & $\begin{array}{l}\text { Propose an extension } \\
\text { of VIKOR method under } \\
\text { Fuzzy Belief Structure } \\
\text { for FMEA. }\end{array}$ & $\checkmark$ & $\checkmark$ & $\checkmark$ & $\checkmark$ & & \\
\hline
\end{tabular}


Table 2. Continued...

\begin{tabular}{|c|c|c|c|c|c|c|c|}
\hline Paper & Proposal & $\begin{array}{l}\text { Pondering } \\
\text { risk factors } \\
\text { weights }\end{array}$ & $\begin{array}{l}\text { Consider } \\
\text { individual } \\
\text { judgments }\end{array}$ & $\begin{array}{l}\text { Deals with } \\
\text { imprecision }\end{array}$ & $\begin{array}{l}\text { Use linguistic } \\
\text { terms for } \\
\text { judgments }\end{array}$ & $\begin{array}{l}\text { Hesitation in the } \\
\text { linguistic terms } \\
\text { parameterization }\end{array}$ & $\begin{array}{l}\text { Hesitation in } \\
\text { the judgment }\end{array}$ \\
\hline Tooranloo (2016) & $\begin{array}{l}\text { Proposed a model } \\
\text { for failure mode and } \\
\text { effects analysis based } \\
\text { on intuitionistic fuzzy } \\
\text { approach. }\end{array}$ & $\checkmark$ & $\checkmark$ & $\checkmark$ & $\checkmark$ & $\checkmark$ & \\
\hline Chang (2016) & $\begin{array}{l}\text { Propose an integrated } \\
\text { method, combining } \\
\text { multiattribute failure } \\
\text { mode analysis } \\
\text { (MAFMA) and 2-tuple } \\
\text { representation. }\end{array}$ & $\checkmark$ & $\checkmark$ & $\checkmark$ & $\checkmark$ & & \\
\hline Guo (2016) & $\begin{array}{l}\text { Combines intuitionistic } \\
\text { fuzzy sets (IFSs) with } \\
\text { evidence theory to } \\
\text { analyze the potential } \\
\text { failure modes. }\end{array}$ & $\checkmark$ & $\checkmark$ & $\checkmark$ & $\checkmark$ & $\checkmark$ & \\
\hline $\begin{array}{l}\text { Huang et al. } \\
\text { (2017) }\end{array}$ & $\begin{array}{l}\text { Applies linguistic } \\
\text { distribution assessments } \\
\text { and employs an } \\
\text { improved TODIM in } \\
\text { FMEA. }\end{array}$ & $\checkmark$ & $\checkmark$ & $\checkmark$ & $\checkmark$ & & \\
\hline $\begin{array}{l}\text { Yazdi et al. } \\
\text { (2017) }\end{array}$ & $\begin{array}{l}\text { Extend FMEA by } \\
\text { considering a group } \\
\text { decision-making under } \\
\text { the fuzzy environment. }\end{array}$ & & $\checkmark$ & $\checkmark$ & $\checkmark$ & & \\
\hline Liu et al. (2017) & $\begin{array}{l}\text { Failure Mode and Effect } \\
\text { Analysis Using Cloud } \\
\text { Model Theory and } \\
\text { PROMETHEE Method. }\end{array}$ & & $\checkmark$ & $\checkmark$ & $\checkmark$ & & \\
\hline $\begin{array}{l}\text { Foroozesh et al. } \\
\text { (2018) }\end{array}$ & $\begin{array}{l}\text { Utilizes IVFSs and } \\
\text { mean-variance- } \\
\text { skewness concepts } \\
\text { by a group of supply } \\
\text { chain-experts to solve a } \\
\text { selection problem. }\end{array}$ & & & $\checkmark$ & $\checkmark$ & & \\
\hline Zhu et al. (2018) & $\begin{array}{l}\text { Failure Mode and } \\
\text { Effects Analysis } \\
\text { Considering Consensus } \\
\text { and Preferences } \\
\text { Interdependence. }\end{array}$ & $\checkmark$ & $\checkmark$ & $\checkmark$ & $\checkmark$ & & \\
\hline $\begin{array}{l}\text { Zhang et al. } \\
\text { (2019) }\end{array}$ & $\begin{array}{l}\text { Proposes a consensus } \\
\text { based group decision } \\
\text { making framework for } \\
\text { FMEA. }\end{array}$ & $\checkmark$ & $\checkmark$ & $\checkmark$ & $\checkmark$ & & $\checkmark$ \\
\hline $\begin{array}{l}\text { Wang et al. } \\
\text { (2018) }\end{array}$ & $\begin{array}{l}\text { A risk evaluation and } \\
\text { prioritization method } \\
\text { for FMEA with prospect } \\
\text { theory and Choquet } \\
\text { integral. }\end{array}$ & & $\checkmark$ & $\checkmark$ & $\checkmark$ & & \\
\hline $\begin{array}{l}\text { Chang et al. } \\
\text { (2018) }\end{array}$ & $\begin{array}{l}\text { Integrates the ordered } \\
\text { weighted geometric } \\
\text { (OWG) operator and } \\
\text { hesitant fuzzy linguistic } \\
\text { term sets. }\end{array}$ & & $\checkmark$ & $\checkmark$ & $\checkmark$ & & $\checkmark$ \\
\hline Our proposal & $\begin{array}{l}\text { Combining FMEA with } \\
\text { DHFS. }\end{array}$ & $\checkmark$ & $\checkmark$ & $\checkmark$ & $\checkmark$ & $\checkmark$ & $\checkmark$ \\
\hline
\end{tabular}

Zhu et al. (2012) proposed a new generalization of the fuzzy sets, the dual hesitant fuzzy sets (DHFS). This representation seeks to combine the intuitionist and hesitant concepts, integrating the advantage of each one of them. The Hesitant Fuzzy Sets were proposed by Torra (2010) and allow the membership degree of an element in a set to be associated with several possible values, enabling the decision maker's hesitation in the definition of the variables that represent his judgment (Zhang et al., 2017). As in intuitionistic fuzzy sets, DHFS also has degrees of membership and non-membership functions; however, these two functions are expressed by several determined numbers rather than a single number, modeling the real-world problems more accurately 
than other generalizations of fuzzy theory. Specifically, DHFS is very useful for group decision-making problems, when it is difficult to determine the membership and non-membership functions ( $\mathrm{Yu}$ et al., 2016). Recently, this approach has been widely used for multicriteria decision-making problems, with the development of new models and theories (Zhang et al., 2017). Calache et al. (2021) present a literature review of dual hesitant fuzzy sets applications.

Zhu et al. (2012) define the concept of dual hesitant fuzzy as an extension of hesitant fuzzy sets. Given a fixed set $\mathrm{U}$, a Dual Hesitant Fuzzy set D in X is represented as: $\tilde{D}=\left\{x, \tilde{h}_{\tilde{D}}(x), \tilde{g}_{\tilde{D}}(x) \mid x \in U\right\}$, in which $\tilde{h}_{\tilde{D}}(x)$ e $\tilde{g}_{\tilde{D}}(x)$ are two sets of some value in the range $[0,1]$ denoting the membership and non-membership degrees of the element $x \in U$ to the set $D$, respectively, with the conditions: $0 \leq \gamma, \eta \leq 1$ e, for all $x \in U \quad \gamma \in \tilde{h}_{\tilde{D}}(x), \eta \in \tilde{g}_{\tilde{D}}(x)$, $\gamma^{+} \in \tilde{h}_{\tilde{D}}^{+}(x)=\cup_{\gamma \in \tilde{h}_{\tilde{D}}(x)} \operatorname{Max}\{\gamma\}, \eta^{+} \in \tilde{g}_{\tilde{D}}(x)=\cup_{\eta \in \tilde{g}_{\tilde{D}}(x)} \operatorname{Max}\{\eta\}$.

The basic operations and properties of the DHFS sets were also presented by Zhu et al. (2012). Given three elements DHFS, $d, d_{1}$ and $d_{2}$, and a non-negative integer $n$, then the basic operations can be presented as Yu et al. (2016):

Union- Sum:

$$
d_{1} \oplus d_{2}=\cup_{\tilde{\gamma}_{1} \in \tilde{h}_{1}, \tilde{\gamma}_{2} \in \tilde{h}_{2}, \tilde{\eta}_{1} \in \tilde{g}_{1}, \tilde{\eta}_{2} \in \tilde{g}_{2}}\left\{\left\{\tilde{\gamma}_{1}+\tilde{\gamma}_{2}-\tilde{\gamma}_{1} \tilde{\gamma}_{2}\right\},\left\{\tilde{\eta}_{1} \tilde{\eta}_{2}\right\}\right\}
$$

Intersection-Multiplication:

$$
d_{1} \otimes d_{2}=\cup_{\tilde{\gamma}_{t} \in \tilde{h}_{1}, \tilde{\gamma}_{2} \in \tilde{h}_{2}, \tilde{\eta}_{1} \in \tilde{g}_{1}, \tilde{\eta}_{2} \in \tilde{g}_{2}}\left\{\left\{\tilde{\gamma}_{1} \tilde{\gamma}_{2}\right\},\left\{\tilde{\eta}_{1}+\tilde{\eta}_{2}-\tilde{\eta}_{1} \tilde{\eta}_{2}\right\}\right\}
$$

Multiplication by $n$ :

$$
n d=\bigcup_{\tilde{\gamma} \in \tilde{h}, \tilde{\eta} \in \tilde{g}}\left\{\left\{1-(1-\tilde{\gamma})^{n}\right\},\left\{\tilde{\eta}^{n}\right\}\right\}
$$

Potentiation by $n$ :

$$
d^{n}=\bigcup_{\tilde{\gamma} \in \tilde{h}, \tilde{\eta} \in \tilde{g}}\left\{\left\{\tilde{\gamma}^{n}\right\},\left\{1-(1-\tilde{\eta})^{n}\right\}\right\}
$$

Based on the concepts proposed by Zhu et al. (2012), Wang et al. (2014) has developed some aggregation operators, including the Dual Hesitant Fuzzy Weighted Average (DHFWA), which is used to calculate weighted averages of judgments based on DHFS linguistic terms (Zeng et al., 2018; Li, 2014).

Let $\tilde{d}_{j}=\left(\tilde{h}_{j}, \tilde{g}_{j}\right)(j=1,2, \ldots, n)$ be a DHFS set of elements and let $\omega=\left(\omega_{1}, \omega_{2}, \ldots, \omega_{n}\right)$ be the vector of weights related to $\tilde{d}_{j}$ with $\sum_{j=1}^{n} \omega_{j}=1$, then the DHFWA aggregation operator can be represented as follows (Wang et al., 2014):

$$
\operatorname{DHFWA}\left(\tilde{d}_{1}, \tilde{d}_{2}, \ldots, \tilde{d}_{n}\right)=\oplus_{j=1}^{n}\left(\omega_{j} \tilde{d}_{j}\right)=\bigcup_{\tilde{\gamma}_{j} \in \tilde{h}_{j}, \tilde{\eta}_{j} \in \tilde{g}_{j}}\left\{\left\{1-\prod_{j=1}^{n}(1-\tilde{\gamma})^{\omega_{j}}\right\},\left\{\prod_{j=1}^{n}(\tilde{\eta})^{\omega_{j}}\right\}\right\}
$$

Let $\tilde{d}_{j}=\left(\tilde{h}_{j}, \tilde{g}_{j}\right)(j=1,2, \ldots, n)$ be a set of DHFS elements, the score function $s\left(d_{j}\right)$ is defined as follows:

$$
S\left(d_{j}\right)=\frac{1}{\# \tilde{h}_{\tilde{\gamma}_{j} \in \tilde{h}_{j}}} \tilde{\tilde{\gamma}}_{j}-\frac{1}{\# \tilde{g}_{\tilde{\eta}_{j} \in \tilde{g}_{j}}} \sum_{j}
$$

Where the $\# \tilde{h}$ and $\# \tilde{g}$ are respectively the number of membership $\left(\tilde{\gamma}_{j} \in \tilde{h}_{j}\right)$ and non-membership $\left(\tilde{\eta}_{j} \in \tilde{g}_{j}\right)$ elements considered in the calculus.

For example, if $S\left(d_{3}\right)>S\left(d_{1}\right)>S\left(d_{2}\right)$, then, $\tilde{d}_{3} \succ \tilde{d}_{1} \succ \tilde{d}_{2}$.

\section{Proposed model}

Figure 1 presents the proposed model for the application of Dual Hesitant Fuzzy Sets for group decision making in the FMEA tool. The proposed model has four main steps: characterization of failure modes, decision makers' judgments, aggregation of judgments and ranking of risks based on the RPN value. They are detailed as follows. 


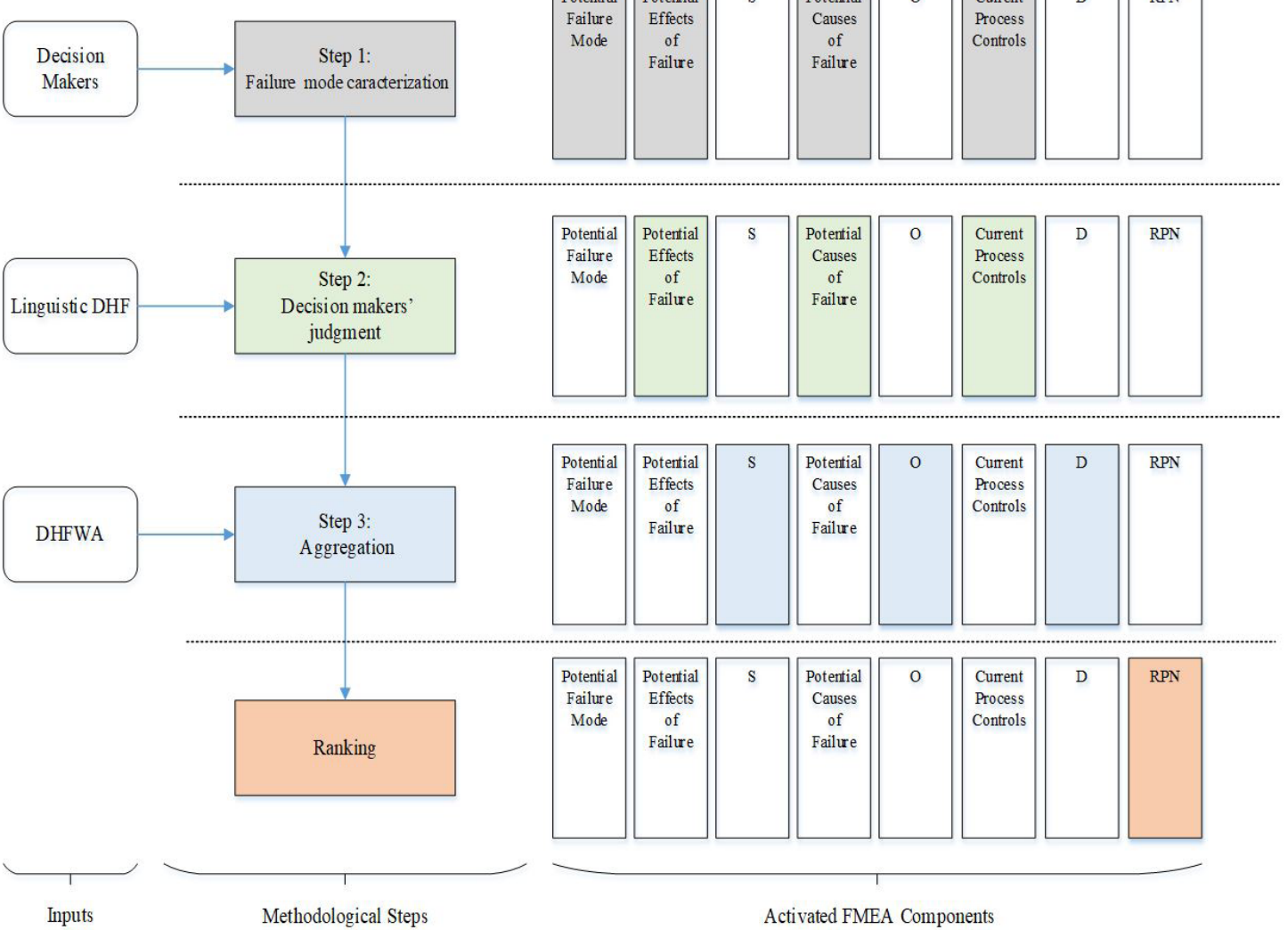

Figure 1. Proposed model for DHF application in FMEA.

Characterization of failure modes: this step consists in defining the risks in focus. To contribute for a better evaluation of decision makers in relation to severity, occurrence and detection, failure modes are detailed, respectively, in relation to the effects of the failure, the potential causes of failure and the current control processes. Qualitative quality management tools, such as the relationship diagram and the lshikawa diagram are typically applied for this step (Tummala \& Schoenherr, 2011; International Electrotechnical Commission, 2009). This step also defines the decision makers who will be responsible for the analysis and judgments of failure modes;

11) Decision makers' judgment: based on the characterization of failure modes, the decision makers should make individual judgments concerning the relative importance of the risk factors (Severity, Occurrence, and Detection) and their level of failure.

Let $\tilde{w}_{k j}=\left(\tilde{h}_{k j}, \tilde{g}_{k j}\right)$ be a group of DHFS elements, the individual assessment $\tilde{w}_{k j}$ on the weight of the risk factors represented by $j=1$ (Severity),2(Occurrence), 3(Detection) is given by $n$ decision makers $D M_{k}(k=1,2, \ldots, n$, . The linguistic terms and respective intuitionist numbers used by decision makers to assess the importance of risk factors are presented in Table 3 as described in Liu et al. (2015a). The judgments collected following the DHFS approach can be presented according to the matrix given by Equation 7 .

Severity Occurrence Detection

\begin{tabular}{|c|c|c|}
\hline$D M_{1}$ & $\tilde{w}_{11}$ & $\tilde{w}_{12}$ \\
\hline $\begin{array}{c}D_{2} \\
\vdots\end{array}$ & $\tilde{w}_{21}$ & $\tilde{w}_{22}$ \\
\hline$D M_{n}$ & $\begin{array}{c}\vdots \\
\tilde{w}_{n 1}\end{array}$ & $\begin{array}{l}\vdots \\
\tilde{w}_{n 2}\end{array}$ \\
\hline
\end{tabular}




\begin{tabular}{ccc}
\hline Linguistic Terms & Membership degree & Non-membership degree \\
\hline Very Low Importance (VL) & 0.10 & 0.85 \\
Low Importance (L) & 0.30 & 0.65 \\
Medium Importance (M) & 0.50 & 0.50 \\
High Importance (H) & 0.75 & 0.20 \\
Very High Importance (VH) & 0.90 & 0.05 \\
\hline
\end{tabular}

Table 4. Linguistic terms and intuitive fuzzy numbers for assessing the level of failure mode in relation to risk factors.

\begin{tabular}{|c|c|c|c|c|}
\hline \multirow{2}{*}{ Linguistic Terms } & \multicolumn{2}{|c|}{ Severity and Occurrence } & \multicolumn{2}{|c|}{ Detection } \\
\hline & Membership degree & Non-membership degree & Membership degree & Non-membership degree \\
\hline (EL) Extremely low & 0.00 & 0.90 & 1.00 & 0.00 \\
\hline (VL) Very low & 0.10 & 0.75 & 0.90 & 0.10 \\
\hline (L) Low & 0.25 & 0.60 & 0.75 & 0.10 \\
\hline (ML) Medium Low & 0.40 & 0.50 & 0.60 & 0.25 \\
\hline (M) Medium & 0.50 & 0.45 & 0.50 & 0.45 \\
\hline$(\mathrm{MH})$ Medium High & 0.60 & 0.25 & 0.40 & 0.50 \\
\hline (H) High & 0.75 & 0.10 & 0.25 & 0.60 \\
\hline (VH) Very High & 0.90 & 0.10 & 0.10 & 0.75 \\
\hline (EH) Extremely High & 1.00 & 0.00 & 0.00 & 0.90 \\
\hline
\end{tabular}

For each decision maker $k$, an individual matrix $\tilde{A}_{k}(k=1,2, \ldots, n$,$) should be used to collect the judgments \tilde{a}_{i j}$ on the level of failure modes $F M_{i},(i=1,2, \ldots, m)$ in relation to the risk factors $j=1,2,3$. Let $a_{i j}=\left(h_{k i j}, g_{k i j}\right)$ be a group of DHFS elements, the matrix given by Equation 8 can be used to collect the DHFS judgments using the linguistic terms and respective fuzzy numbers presented in Table 4 (Liu et al., 2015a).

Severity Occurrence Detection

$$
\tilde{A}_{k}=\begin{gathered}
F M_{1} \\
F M_{2} \\
\vdots \\
F M_{m}
\end{gathered}\left(\begin{array}{cccc}
\tilde{a}_{11}^{k} & \tilde{a}_{12}^{k} & \tilde{a}_{13}^{k} \\
\tilde{a}_{21}^{k} & \tilde{a}_{22}^{k} & \tilde{a}_{23}^{k} \\
\vdots & \vdots & \vdots \\
\tilde{a}_{m 1}^{k} & \tilde{a}_{m 2}^{k} & \tilde{a}_{m 3}^{k}
\end{array}\right)
$$

III) Aggregation of the judgments: the judgments collected in the previous phase will be aggregated through the application of the dual hesitant fuzzy aggregation operator (DHFWA), and the scores are calculated according to Equations 5 and 6 , related to $k=1,2, \ldots, n$ decision makers. As a result of this aggregation, a vector of weights is obtained, $W_{j}(j=1,2,3)$ that represent the importance of risk factors, and an aggregated matrix of judgments $A_{i j},(i=1,2, \ldots, m ; j=1,2,3)$ of the failure modes, according to the matrix given by Equation 9 .

\section{Severity Occurrence Detection}

$$
\begin{gathered}
F M_{1} \\
F M_{2} \\
\vdots \\
F M_{m}
\end{gathered}\left(\begin{array}{ccc}
A_{11} & A_{12} & A_{13} \\
A_{21} & A_{22} & A_{23} \\
\vdots & \vdots & \vdots \\
A_{m 1} & A_{m 2} & A_{m 3}
\end{array}\right)
$$

The results obtained by the aggregation are contained in the range between $[-1,1]$. To enable RPN calculation, the aggregated results need to be converted to scales compatible with traditional FMEA. For the translation of values $W_{j}$ which represent the weights of the risk factors, Equation 10 must be used and then the values must be weighted, resulting in the weight vector $\omega_{j}(j=1,2,3) \in[0,1]$. Then this weight vector should be normalized such that $\sum_{j=1}^{3} S_{j}=1$. For the translation of values $A_{i j}$, which represent the aggregate evaluations for each failure mode $i$ in relation to each risk factor $j$, Equation 11 must be applied, resulting in the value $R_{i j}(i=1,2, \ldots, m ; j=1,2,3) \in[1,10]$. 


$$
\begin{gathered}
\omega_{j}=0.5 w_{j}+0.5 \forall j=1,2,3 . \\
R_{i j}=4.5 A_{i j}+5.5 \forall i=1,2, \ldots, m ; j=1,2,3 .
\end{gathered}
$$

IV) Ranking of the failure modes: the value of the $R P N_{i}(i=1,2, \ldots, m)$ for each failure mode is calculated by means of the weighted multiplication according to Equation 12. The failure modes with higher values of $R P N_{i}$ should be prioritized for mitigation.

$$
R P N_{i}=\left[\left(R_{i 1}\right)^{S_{l}} \cdot\left(R_{i 2}\right)^{S_{2}} \cdot\left(R_{i 3}\right)^{S_{3}}\right] \forall i=1,2, \ldots, m
$$

\section{1llustrative application}

The analysis of potential failure modes of a supplier is an important activity of supply chain management, due to the impact that potential failure modes have on the performance of a supply chain (He \& Yang, 2018; Wu et al., 2006). For the evaluation of supplier potential failure modes, the FMEA tool is widely applied, for example, Valinejad \& Rahmani (2018) evaluate the failure modes in the internet service providers; Foroozesh et al. (2018) assess sustainable-suppliers for manufacturing services; Ghadge et al. (2017) present an application in a printed circuit board supply chain; among others. In this way, an illustrative application related to supplier potential failure modes was developed following the steps proposed by the model described in Section 5 .

Characterization of failure modes: assume a group of decision makers, composed of a production manager (DM1), a purchasing manager (DM2) and a quality manager (DM3) with respective weights [0.4;0.3;0.3], which evaluated 6 potential failure modes, presented in Table 5, in relation to the traditional FMEA risk factors (Severity, Occurrence and Detection). DMs used quality tools such as relationship diagram and lshikawa diagram to analyze failure modes. These tools complement the FMEA in managing information and improving the failure modes understanding;

11) Decision-makers' judgment: Table 6 presents the judgments of each decision maker on the risk factors importance using the linguistic terms in Table 3.

Each of the decision makers made judgments on the levels of failure modes according to risk factors using the linguistic terms in Table 4. The results of these assessments are presented in Tables 7 to 9 with the abbreviations of the linguistic terms provided by the decision makers.

In this case, each of the decision makers has the autonomy to judge the failure modes according to their respective points of view. In this way, differences between judgments can happen. The procedure of judgment aggregation, presented in the next step, seeks to consider these different points of view from different areas of the organization to obtain a more systemic view of the impacts of failure modes. In addition, the process of collecting judgments and presenting information in tables can contribute to the presentation of these different points of view that can be used in a consensus search for the development of improvement action plans.

111) Aggregation of the judgments: In order to elucidate the application of the presented equations, the severity weight calculation is detailed. Equation 5 is applied to obtain the aggregated values for the weight of the risk factors as shown in Equation 13. Then, Equation 6 is used to find the dual hesitant fuzzy score, as presented by Equation 14. The translated score is obtained through the use of Equation 10, as demonstrated in Equation 15. The normalized value is obtained by the sum as presented in Equation 16. The same procedure is carried out for the calculation of the other risk factors weights, and the results are exhibit in Table 10.

$$
\begin{gathered}
\operatorname{DHFWA}\left(\tilde{w}_{11}, \tilde{w}_{21}, \tilde{w}_{31}\right)=\left\{\left\{1-\left(0.9^{0.4} * 0.75^{0.3} * 0.9^{0.3}\right)\right\},\left\{0.05^{0.4} * 0.20^{\left.\left.0.3 * 0.05^{0.3}\right\}\right\}=\{0.868\},\{0.076\}}\right.\right. \\
S\left(W_{1}\right)=0.868-0.076=0.792 \\
\omega_{1}=0.5^{*} 0.792+0.5=0.896 \\
S_{1}=\frac{0.896}{0.896+0.532+0.489}=0.372
\end{gathered}
$$


Table 5: Supply failure modes used in FMEA evaluation.

\begin{tabular}{|c|c|c|c|}
\hline & Potential Failure Effect & Potential Cause of Failure & Current process of control \\
\hline \multirow{3}{*}{$\begin{array}{l}\boldsymbol{F M}_{1} \text { - Supplier's inability to } \\
\text { meet quality requirements }\end{array}$} & $\begin{array}{l}\text {-Production of non-conforming } \\
\text { products; }\end{array}$ & -Lack of process control; & - Sampling inspection. \\
\hline & $\begin{array}{l}\text {-Commitment of the image with } \\
\text { customers; }\end{array}$ & -Material used inappropriate; & \\
\hline & - Loss of product quality. & -Lack of training & \\
\hline \multirow{2}{*}{$\begin{array}{l}\boldsymbol{F} \boldsymbol{M}_{2} \text { - Can not provide } \\
\text { competitive pricing }\end{array}$} & - Higher production costs; & - High transportation cost & - Benchmarking \\
\hline & - Decrease in profit margin. & & \\
\hline \multirow{5}{*}{$\begin{array}{c}\boldsymbol{F} \boldsymbol{M}_{3} \text { - Low supplier financial } \\
\text { health }\end{array}$} & $\begin{array}{l}\text { - Increase in the cost of } \\
\text { production; }\end{array}$ & - Inefficient management; & - Audit programs. \\
\hline & - Late delivery; & - Low sales volume. & \\
\hline & - Fines for delay; & & \\
\hline & - Do not deliver products; & & \\
\hline & $\begin{array}{l}\text {-Commitment of the image with } \\
\text { the client. }\end{array}$ & & \\
\hline \multirow[t]{2}{*}{$\begin{array}{l}\boldsymbol{F M}_{4} \text { - Inability to cope with } \\
\text { changes in volume demand }\end{array}$} & $\begin{array}{c}\text { - Do not deliver products; } \\
\text { - Late delivery; } \\
\text { - Fines for delay; }\end{array}$ & $\begin{array}{l}\text {-Ineffective communication; } \\
\text {-Lack of capacity. }\end{array}$ & $\begin{array}{l}\text { - Communication by e-mail and } \\
\text { telephone; }\end{array}$ \\
\hline & $\begin{array}{l}\text {-Commitment of the image with } \\
\text { the client. }\end{array}$ & & \\
\hline \multirow[t]{3}{*}{$\begin{array}{l}\boldsymbol{F M}_{5} \text { - Lack of integration } \\
\text { between customer and supplier }\end{array}$} & $\begin{array}{c}\text { - Unbalance of production; } \\
\text { - Late delivery; } \\
\text { - Fines for delay; }\end{array}$ & -Ineffective communication; & - No control process. \\
\hline & $\begin{array}{l}\text {-Commitment of the image with } \\
\text { the client; }\end{array}$ & & \\
\hline & - Increased cost of raw material. & & \\
\hline \multirow{3}{*}{$\begin{array}{c}\boldsymbol{F M}_{6}-\text { Failure to meet delivery } \\
\text { requirements }\end{array}$} & - Delays in production; & -Cargo theft. & $\begin{array}{l}\text { - Monitoring of arrival times in the } \\
\text { logistics sector. }\end{array}$ \\
\hline & - Fines for delay; & & \\
\hline & $\begin{array}{l}\text {-Commitment of the image with } \\
\text { the client. }\end{array}$ & & \\
\hline
\end{tabular}

Table 6. Judgments of the importance of risk factors according to decision makers.

\begin{tabular}{cccc}
\hline & Severity & Occurrence & Detection \\
\hline $\boldsymbol{D} M_{1}$ & $\mathrm{VH}$ & $\mathrm{H}, \mathrm{VH}$ & $\mathrm{H}$ \\
$\boldsymbol{D M}_{2}$ & $\mathrm{H}$ & $\mathrm{M}$ & $\mathrm{H}$ \\
$\boldsymbol{D M}_{3}$ & $\mathrm{VH}$ & $\mathrm{H}$ & $\mathrm{M}, \mathrm{H}$ \\
\hline
\end{tabular}

Table 7. Judgments of the $\boldsymbol{D} \boldsymbol{M}_{1}$ on the levels of failure modes according to each risk factor.

\begin{tabular}{cccc}
\hline $\boldsymbol{D M}_{1}$ & Severity & Occurrence & Detection \\
\hline $\boldsymbol{F} M_{1}$ & $\mathrm{H}, \mathrm{VH}$ & $\mathrm{L}, \mathrm{ML}$ & $\mathrm{MH}, \mathrm{H}$ \\
$\boldsymbol{F M}_{2}$ & $\mathrm{VH}, \mathrm{EH}$ & $\mathrm{M}, \mathrm{MH}$ & $\mathrm{H}$ \\
$\boldsymbol{F M}_{3}$ & $\mathrm{H}, \mathrm{VH}$ & $\mathrm{M}$ & $\mathrm{MH}$ \\
$\boldsymbol{F M}_{4}$ & $\mathrm{H}$ & $\mathrm{H}, \mathrm{VH}$ & $\mathrm{L}, \mathrm{ML}$ \\
$\boldsymbol{F M}_{5}$ & $\mathrm{M}, \mathrm{MH}$ & $\mathrm{H}$ & $\mathrm{ML}, \mathrm{M}$ \\
\hline
\end{tabular}


Table 8. Judgments of the $\boldsymbol{D} \boldsymbol{M}_{2}$ on the levels of failure modes according to each risk factor.

\begin{tabular}{cccc}
\hline $\boldsymbol{M M}_{2}$ & Severity & Occurrence & Detection \\
\hline $\boldsymbol{F M}$ & $\mathrm{H}, \mathrm{VH}$ & $\mathrm{ML}, \mathrm{M}$ & $\mathrm{M}, \mathrm{MH}$ \\
$\boldsymbol{F M}_{2}$ & $\mathrm{H}$ & $\mathrm{M}, \mathrm{VH}$ & $\mathrm{VH}$ \\
$\boldsymbol{F M}_{3}$ & $\mathrm{M}, \mathrm{MH}$ & $\mathrm{HL}, \mathrm{M}, \mathrm{MH}$ & $\mathrm{M}$ \\
$\boldsymbol{F M}_{4}$ & $\mathrm{M}$ & $\mathrm{VH}$ & $\mathrm{ML}, \mathrm{M}, \mathrm{MH}$ \\
\hline $\boldsymbol{F M}_{5}$ & $\mathrm{~L}, \mathrm{ML}$ & $\mathrm{VL}$ & $\mathrm{H}, \mathrm{VH}$
\end{tabular}

Table 9. Judgments of the $\boldsymbol{D M}_{3}$ on the levels of failure modes according to each risk factor.

\begin{tabular}{cccc}
\hline $\boldsymbol{M M}_{3}$ & Severity & Occurrence & Detection \\
\hline $\boldsymbol{F M}_{1}$ & $\mathrm{VH}, \mathrm{EH}$ & $\mathrm{VL}, \mathrm{L}$ & $\mathrm{L}, \mathrm{ML}, \mathrm{M}$ \\
$\boldsymbol{F M}_{2}$ & $\mathrm{~L}, \mathrm{ML}, \mathrm{M}$ & $\mathrm{ML}, \mathrm{M}$ & $\mathrm{MH}, \mathrm{H}$ \\
$\boldsymbol{F M}_{3}$ & $\mathrm{~L}, \mathrm{ML}$ & $\mathrm{L}, \mathrm{ML}, \mathrm{H}$ & $\mathrm{H}, \mathrm{VH}, \mathrm{EH}$ \\
$\boldsymbol{F M}_{4}$ & $\mathrm{MH}, \mathrm{H}$ & $\mathrm{H}, \mathrm{VH}$ & $\mathrm{M} ; \mathrm{MH}$ \\
$\boldsymbol{F M}_{5}$ & $\mathrm{MH}, \mathrm{H}$ & $\mathrm{H}, \mathrm{VH}$ & $\mathrm{M}, \mathrm{MH}$ \\
\hline
\end{tabular}

Table 10. Aggregated weights of risk factors.

\begin{tabular}{cccc}
\hline & Severity & Occurrence & Detection \\
\hline Aggregated score & 0.792 & 0.532 & 0.489 \\
Translated and weighted score & 0.372 & 0.318 & 0.309 \\
\hline
\end{tabular}

In the same way, the calculation for the aggregated scores for the $\boldsymbol{F M}_{1}$ in the risk factor severity is detailed as follows. The DHFWA aggregated value is obtained by Equation 5, as show in Equation 17. Then, the DHF score calculation presented in Equation 18 is obtained using Equation 6. To get the translated score for the failure modes levels, Equation 11 is used, as presented by Equation 19. The aggregated scores are presented in Table 11.

$$
\begin{aligned}
& \text { DHFWA }\left(\tilde{a}_{11}^{1}, \tilde{a}_{11}^{2}, \tilde{a}_{11}^{3}\right)=\left\{\left\{1-\left(0.75^{0.4} * 0.75^{0.3} * 0.90^{0.3}\right)\right\},\left\{0.10^{0.4} * 0.10^{0.3} * 0.10^{0.3}\right\}\right\} \\
& \left\{\left\{1-\left(0.90^{0.4} * 0.75^{0.3} * 0.90^{0.3}\right)\right\},\left\{0.10^{0.4} * 0.10^{0.3} * 0.10^{0.3}\right\}\right\} \\
& \left\{\left\{1-\left(0.75^{0.4} * 0.90^{0.3} * 0.9^{0.3}\right)\right\},\left\{0.10^{0.4} * 0.10^{0.3} * 0.10^{0.3}\right\}\right\} ; \\
& \left\{\left\{1-\left(0.75^{0.4} * 0.75^{0.3} * 0.9^{0.3}\right)\right\},\left\{0.10^{0.4} * 0.10^{0.3} * 0.0^{0.3}\right\}\right\} ; \\
& \left\{\left\{1-\left(0.75^{0.4} * 0.75^{0.3} * 1.0^{0.3}\right)\right\},\left\{0.10^{0.4} * 0.10^{0.3} * 0.0^{0.3}\right\}\right\} ; \\
& \left\{\left\{1-\left(0.90^{0.4} * 0.75^{0.3} * 1.0^{0.3}\right)\right\},\left\{0.10^{0.4} * 0.10^{0.3} * 0.0^{0.3}\right\}\right\} \\
& =\{0.810,0.868,0.856,1.0,1.0,1.0\}\{0.1,0.1,0.1,0.0,0.0,0.0\}
\end{aligned}
$$


Table 11. Aggregated scores for failure mode levels in each risk factor.

\begin{tabular}{|c|c|c|c|c|c|c|}
\hline & \multicolumn{3}{|c|}{ Aggregated score } & \multicolumn{3}{|c|}{ Translated score } \\
\hline & Severity & Occurrence & Detection & Severity & Occurrence & Detection \\
\hline $\boldsymbol{F} \boldsymbol{M}_{1}$ & 0.872 & -0.230 & 0.152 & 9.424 & 4.464 & 6.184 \\
\hline$F M_{2}$ & 0.799 & 0.099 & -0.297 & 9.096 & 5.944 & 4.162 \\
\hline$F M_{3}$ & 0.420 & -0.047 & -0.430 & 7.391 & 5.289 & 3.564 \\
\hline$F M_{4}$ & 0.487 & 0.714 & -0.209 & 7.692 & 8.712 & 4.559 \\
\hline $\boldsymbol{F M}_{5}$ & 0.228 & 0.733 & 0.264 & 6.525 & 8.798 & 6.689 \\
\hline $\boldsymbol{F M}_{6}$ & 0.714 & -0.420 & 0.096 & 8.712 & 3.610 & 5.931 \\
\hline
\end{tabular}

$$
\begin{gathered}
S\left(A_{i j}\right)=\frac{1}{6}(0.810+0.868+0.856+1.0+1.0+1.0)-\frac{1}{6}(0.10+0.10+0.10+0.0+0.0+0.0)=0.872 \\
R_{i j}=4.5 * 0.872+5.5=9.425
\end{gathered}
$$

IV) Ranking of failure modes: the value of the $\operatorname{RPN}_{i}(i=1,2, \ldots, m)$ for each failure mode computed by Equation 12 and the respective priority order of mitigation is given in Table 12 below. For this illustrative application failure mode of lack of integration between customer and supplier $\left(\boldsymbol{F M} \boldsymbol{M}_{5}\right)$ is presented with higher mitigation priority.

It should be noted that the proposed model has a compensatory nature in which it considers the aggregated judgments of the decision makers and the risk factors weights. Thus, all the risk factors are used for the priority definition. For example, $\boldsymbol{F} \boldsymbol{M}_{1}$ has a higher score in the severity and detection factors than $\boldsymbol{F M}_{4}$, but the score of occurrence in $\boldsymbol{F M}_{4}$ is much bigger than in $\boldsymbol{F M}_{1}$. Although the value of the RPN of the two failure modes are very close, the $\boldsymbol{F M}_{4}$ RPN is higher due to the compensation between the evaluated criteria.

Explanation of the problem using FMEA enables team discussions in the search for consensus for continuous improvement actions. For example, the most critical failure mode was $F M_{5}$ with the highest RPN, presented in Table 12. The results in Table 11 show that the most critical risk factors are related to potential cause and control. Thus, based on the information in Table 5, DMs should discuss these results and action plans aimed at 1) improving communication with suppliers to address the potential cause of the failure and 2) creating a control process for this failure mode.

Table 12. RPN result and failure modes Ranking.

\begin{tabular}{ccc}
\hline Failure Modes & RPN & Ranking \\
\hline $\boldsymbol{F} \boldsymbol{M}_{1}$ & 6.509 & 3 \\
$\boldsymbol{F M}_{2}$ & 6.226 & 6 \\
$\boldsymbol{F M}_{3}$ & 5.294 & 2 \\
$\boldsymbol{F M}_{4}$ & 6,794 & 1 \\
$\boldsymbol{F M}$ & 7.217 & 5
\end{tabular}

\section{Conclusion}

Current quality management is highly concerned with managing the potential failures of a process, system, or product. This concern was reaffirmed with the update of 1S0 9001: 2015. To deal with the evaluation and 
prioritization of potential failures, the FMEA tool is widely used in the literature. The techniques based on hesitant fuzzy and intuitionistic fuzzy representations have been applied to deal with the group decision making problem, however, each one deals with a type of hesitation. Therefore, the Dual Hesitant Fuzzy technique was proposed to combine the advantages of Hesitant Fuzzy and Intuitionistic Fuzzy, providing a greater ability to deal with hesitations.

Thus, this article presented a new proposal that integrates the FMEA tool with the Dual Hesitant Fuzzy technique for group decision making to deal with the hesitation in the evaluation and prioritization of failure modes. It provides a more appropriate treatment of expert hesitation than other FMEA approaches found in the literature, based on Hesitant Fuzzy or Intuitionistic Fuzzy. Models based on Hesitant Fuzzy deal only with hesitation related to the activation of one or more linguistic terms for a variable, while those based on Intuitionistic Fuzzy deal only with the hesitation regarding the definition of the fuzzy number representing the linguistic term. This proposal based on the Dual Hesitant Fuzzy addresses the hesitation by means of these two combined ways. In addition, an application model was proposed following four steps: characterization of failure modes, judgments of decision makers, aggregation of judgments and ranking of risks based on the RPN weighted calculation. Finally, an illustrative application for failure modes in the context of supply risk management was developed to elucidate the steps of the proposed model.

Through the illustrative application, it is possible to verify that the proposed model combining FMEA and DHFS can easily be replicated in several real problems. The main practical implications of this combination are:

- ability to deal with group decision making considering individual judgments;

- the treatment of the subjectivity generated by hesitation in the evaluation of risk factors;

- the use of linguistic terms to represent the judgments of decision makers;

- it deals with decision makers with different importance and;

- it considers risk factors with varying weights according to the addressed context.

As a limitation of the study, the proposed model does not deal with the interrelation between failure modes and does not verify the interrelationship between the risk factors. In this way, the proposed model can be improved in future studies to overcome these limitations. Finally, additional studies can be conducted in different application contexts in order to further explore the applicability of the proposed model.

\section{Acknowledgements}

Funding: This work was supported by the São Paulo Research Foundation - FAPESP (grant number 2018/21129-5); Coordination for higher Education Staff Development - CAPES (grant number 001); and National Council for Scientific and Technological Development CNPQ (307064/2017-4).

\section{References}

Abdelgawad, M., \& Fayek, A. R. (2010). Risk management in the construction industry using combined fuzzy FMEA and fuzzy AHP. Journal of Construction Engineering and Management, 136(9), 1028-1036. http://dx.doi.org/10.1061/(ASCE)C0.1943-7862.0000210.

Akyuz, E., \& Celik, E. (2018). A quantitative risk analysis by using interval type-2 fuzzy FMEA approach: the case of oil spill. Maritime Policy \& Management, 45(8), 979-994. http://dx.doi.org/10.1080/03088839.2018.1520401.

Arabsheybani, A., Paydar, M. M., \& Safaei, A. S. (2018). An integrated fuzzy MOORA method and FMEA technique for sustainable supplier selection considering quantity discounts and supplier's risk. Journal of Cleaner Production, 190, 577-591. http://dx.doi. org/10.1016/j.jclepro.2018.04.167.

Bahrebar, S., Blaabjerg, F., Wang, H., Vafamand, N., Khooban, M. H., Rastayesh, S., \& Zhou, D. (2018). A novel type-2 fuzzy logic for improved risk analysis of proton exchange membrane fuel cells in marine power systems application. Energies, 11(4), 721. http:// dx.doi.org/10.3390/en11040721.

Bonfant, G., Belfanti, P., Paternoster, G., Gabrielli, D., Gaiter, A. M., Manes, M., \& Nebiolo, P. E. (2010). Clinical risk analysis with failure mode and effect analysis (FMEA) model in a dialysis unit. Journal of Nephrology, 23(1), 111.

Calache, L. D. D. R. (2018). Comparação de técnicas fuzzy para a decisão em grupo aplicadas à seleção de fornecedores (Dissertação de mestrado). Universidade de São Paulo, São Carlos.

Calache, L. D. D. R., Arantes, R. F. M., Zanon, L. G., Osiro, L., \& Carpinetti, L. C. R. (2021). A literature review of dual hesitant fuzzy sets. Brazilian Journal of Development, X(1), 10972-10988. http://dx.doi.org/10.34117/bjdv7n1-750.

Can, G. F. (2018). An intutionistic approach based on failure mode and effect analysis for prioritizing corrective and preventive strategies. Human Factors and Ergonomics in Manufacturing \& Service Industries, 28(3), 130-147. http://dx.doi.org/10.1002/hfm.20729. 
Chai, K. C., Jong, C. H., Tay, K. M., \& Lim, C. P. (2016). A perceptual computing-based method to prioritize failure modes in failure mode and effect analysis and its application to edible bird nest farming. Applied Soft Computing, 49, 734-747. http://dx.doi. org/10.1016/j.asoc.2016.08.043.

Chang, K. H. (2016). Generalized multi-attribute failure mode analysis. Neurocomputing, 175, 90-100. http://dx.doi.org/10.1016/j. neucom.2015.10.039.

Chang, K. H., Wen, T. C., \& Chung, H. Y. (2018). Soft failure mode and effects analysis using the OWG operator and hesitant fuzzy linguistic term sets. Journal of Intelligent \& Fuzzy Systems, 34(4), 2625-2639. http://dx.doi.org/10.3233/JIFS-17594.

Chaudhuri, A., Mohanty, B. K., \& Singh, K. N. (2013). Supply chain risk assessment during new product development: a group decision making approach using numeric and linguistic data. International Journal of Production Research, 51(10), 2790-2804. http://dx.doi. org/10.1080/00207543.2012.654922.

Chen, P. S., \& Wu, M. T. (2013). A modified failure mode and effects analysis method for supplier selection problems in the supply chain risk environment: a case study. Computers \& Industrial Engineering, 66(4), 634-642. http://dx.doi.org/10.1016/j.cie.2013.09.018.

Chin, K. S., Chan, A., \& Yang, J. B. (2008). Development of a fuzzy FMEA based product design system. International Journal of Advanced Manufacturing Technology, 36(7-8), 633-649. http://dx.doi.org/10.1007/s00170-006-0898-3.

Chin, K. S., Wang, Y. M., Poon, G. K. K., \& Yang, J. B. (2009). Failure mode and effects analysis using a group-based evidential reasoning approach. Computers \& Operations Research, 36(6), 1768-1779. http://dx.doi.org/10.1016/j.cor.2008.05.002.

Chiozza, M. L., \& Ponzetti, C. (2009). FMEA: a model for reducing medical errors. Clinica Chimica Acta, 404(1), 75-78. http://dx.doi. org/10.1016/j.cca.2009.03.015. PMid:19298799.

Chrysostom, S., \& Dwivedi, R. K. (2013). A review on the methodologies used in failure modes and effects analysis (FMEA). International Journal of Mechanical and Production Engineering, 1(6), 12-15.

Fattahi, R., \& Khalilzadeh, M. (2018). Risk evaluation using a novel hybrid method based on FMEA, extended MULTIMOORA, and AHP methods under fuzzy environment. Safety Science, 102, 290-300. http://dx.doi.org/10.1016/j.ssci.2017.10.018.

Fonseca, L. M. (2015). From Quality Gurus and TQM to $1 S 0$ 9001: 2015: a review of several quality paths. International Journal of Qualitative Research, 9(1), 167-180.

Fonseca, L., \& Domingues, J. P. (2017). ISO 9001: 2015 edition-management, quality and value. International Journal of Qualitative Research, 1(11), 149-158.

Foroozesh, N., Tavakkoli-Moghaddam, R., \& Mousavi, S. M. (2018). Sustainable-supplier selection for manufacturing services: a failure mode and effects analysis model based on interval-valued fuzzy group decision-making. International Journal of Advanced Manufacturing Technology, 95(9-12), 3609-3629. http://dx.doi.org/10.1007/s00170-017-1308-8.

Geramian, A., Mehregan, M. R., Garousi Mokhtarzadeh, N., \& Hemmati, M. (2017). Fuzzy inference system application for failure analyzing in automobile industry. International Journal of Quality \& Reliability Management, 34(9), 1493-1507. http://dx.doi. org/10.1108/1JQRM-03-2016-0026.

Ghadge, A., Fang, X., Dani, S., \& Antony, J. (2017). Supply chain risk assessment approach for process quality risks. International Journal of Quality \& Reliability Management, 34(7), 940-954. http://dx.doi.org/10.1108/1JQRM-01-2015-0010.

Guo, J. (2016). A risk assessment approach for failure mode and effects analysis based on intuitionistic fuzzy sets and evidence theory. Journal of Intelligent \& Fuzzy Systems, 30(2), 869-881. http://dx.doi.org/10.3233/IFS-151809.

Hajiagha, S. H. R., Hashemi, S. S., Mohammadi, Y., \& Zavadskas, E. K. (2016). Fuzzy belief structure based VIKOR method: an application for ranking delay causes of Tehran metro system by FMEA criteria. Transport, 31(1), 108-118. http://dx.doi.org/10.3846/1648414 2.2016.1133454.

He, B., \& Yang, Y. (2018). Mitigating supply risk: an approach with quantity flexibility procurement. Annals of Operations Research, 271(2), 599-617. http://dx.doi.org/10.1007/s10479-018-2840-0.

Helvacioglu, S., \& Ozen, E. (2014). Fuzzy based failure modes and effect analysis for yacht system design. Ocean Engineering, 79, 131141. http://dx.doi.org/10.1016/j.oceaneng.2013.12.015.

Hu, Y. P., You, X. Y., Wang, L., \& Liu, H. C. (2019). An integrated approach for failure mode and effect analysis based on uncertain linguistic GRA-TOPSIS method. Soft Computing, 23(18), 8801-8814. http://dx.doi.org/10.1007/s00500-018-3480-7.

Huang, J., Li, Z. S., \& Liu, H. C. (2017). New approach for failure mode and effect analysis using linguistic distribution assessments and TODIM method. Reliability Engineering \& System Safety, 167, 302-309. http://dx.doi.org/10.1016/j.ress.2017.06.014.

Huang, Z., Jiang, W., \& Tang, Y. (2018). A new method to evaluate risk in failure mode and effects analysis under fuzzy information. Soft Computing, 22(14), 4779-4787. http://dx.doi.org/10.1007/s00500-017-2664-x.

International Electrotechnical Commission - IEC. (2009). IEC/FDIS 31010: risk management: risk assessment techniques. Local.

Jenab, K., \& Dhillon, B. S. (2005). Group-based failure effects analysis. International Journal of Reliability Quality and Safety Engineering, 12(04), 291-307. http://dx.doi.org/10.1142/S0218539305001835.

Jiang, W., Xie, C., Zhuang, M., \& Tang, Y. (2017). Failure mode and effects analysis based on a novel fuzzy evidential method. Applied Soft Computing, 57, 672-683. http://dx.doi.org/10.1016/j.asoc.2017.04.008.

Kabir, S., \& Papadopoulos, Y. (2018). A review of applications of fuzzy sets to safety and reliability engineering. International Journal of Approximate Reasoning, 100, 29-55. http://dx.doi.org/10.1016/j.jjar.2018.05.005.

Ko, W. C. (2013). Exploiting 2-tuple linguistic representational model for constructing HOQ-based failure modes and effects analysis. Computers \& Industrial Engineering, 64(3), 858-865. http://dx.doi.org/10.1016/j.cie.2012.11.016.

Kumru, M., \& Kumru, P. Y. (2013). Fuzzy FMEA application to improve purchasing process in a public hospital. Applied Soft Computing, 13(1), 721-733. http://dx.doi.org/10.1016/j.asoc.2012.08.007.

Li, Y. M. (2014). An approach to evaluate the clothing creative design with dual hesitant fuzzy information. Journal of Control Science and Engineering, 2014, 11. http://dx.doi.org/10.1155/2014/352619.

Li, X., He, M., \& Wang, H. (2017). Application of failure mode and effect analysis in managing catheter-related blood stream infection in intensive care unit. Medicine, 96(51), e9339. http://dx.doi.org/10.1097/MD.0000000000009339. PMid:29390515. 
Lin, C. Y., Lee, A. H., \& Kang, H. Y. (2015). An integrated new product development framework-an application on green and low-carbon products. International Journal of Systems Science, 46(4), 733-753. http://dx.doi.org/10.1080/00207721.2013.798447.

Liu, H. C., Liu, L., Liu, N., \& Mao, L. X. (2012). Risk evaluation in failure mode and effects analysis with extended VIKOR method under fuzzy environment. Expert Systems with Applications, 39(17), 12926-12934. http://dx.doi.org/10.1016/j.eswa.2012.05.031.

Liu, H. C., Liu, L., \& Liu, N. (2013). Risk evaluation approaches in failure mode and effects analysis: a literature review. Expert Systems with Applications, 4O(2), 828-838. http://dx.doi.org/10.1016/j.eswa.2012.08.010.

Liu, H. C., Fan, X. J., Li, P., \& Chen, Y. Z. (2014a). Evaluating the risk of failure modes with extended MULTIMOORA method under fuzzy environment. Engineering Applications of Artificial Intelligence, 34, 168-177. http://dx.doi.org/10.1016/j.engappai.2014.04.011.

Liu, H. C., You, J. X., \& You, X. Y. (2014b). Evaluating the risk of healthcare failure modes using interval 2-tuple hybrid weighted distance measure. Computers \& Industrial Engineering, 78, 249-258. http://dx.doi.org/10.1016/j.cie.2014.07.018.

Liu, H. C., Liu, L., \& Li, P. (2014c). Failure mode and effects analysis using intuitionistic fuzzy hybrid weighted Euclidean distance operator. International Journal of Systems Science, 45(10), 2012-2030. http://dx.doi.org/10.1080/00207721.2012.760669.

Liu, H. C., You, J. X., Shan, M. M., \& Shao, L. N. (2015a). Failure mode and effects analysis using intuitionistic fuzzy hybrid TOPSIS approach. Soft Computing, 19(4), 1085-1098. http://dx.doi.org/10.1007/s00500-014-1321-x.

Liu, H. C., You, J. X., You, X. Y., \& Shan, M. M. (2015b). A novel approach for failure mode and effects analysis using combination weighting and fuzzy VIKOR method. Applied Soft Computing, 28, 579-588. http://dx.doi.org/10.1016/j.asoc.2014.11.036.

Liu, H. C., Li, P., You, J. X., \& Chen, Y. Z. (2015c). A novel approach for FMEA: combination of interval 2-tuple linguistic variables and gray relational analysis. Quality and Reliability Engineering International, 31(5), 761-772. http://dx.doi.org/10.1002/qre.1633.

Liu, H. C., Li, Z., Song, W., \& Su, Q. (2017). Failure mode and effect analysis using cloud model theory and PROMETHEE method. IEEE Transactions on Reliability, 66(4), 1058-1072. http://dx.doi.org/10.1109/TR.2017.2754642.

Lolli, F., Ishizaka, A., Gamberini, R., Rimini, B., \& Messori, M. (2015). FlowSort-GDSS-A novel group multi-criteria decision support system for sorting problems with application to FMEA. Expert Systems with Applications, 42(17-18), 6342-6349. http://dx.doi. org/10.1016/j.eswa.2015.04.028.

Lorenzi, C. 1., \& Ferreira, J. C. E. (2018). Failure mapping using FMEA and A3 in engineering to order product development: a case study in the industrial automation sector. International Journal of Quality \& Reliability Management, 35(7), 1399. http://dx.doi. org/10.1108/IJQRM-10-2016-0179.

Mirghafoori, S. H., lzadi, M. R., \& Daei, A. (2018). Analysis of the barriers affecting the quality of electronic services of libraries by VIKOR, FMEA and entropy combined approach in an intuitionistic-fuzzy environment. Journal of Intelligent \& Fuzzy Systems, 34(4), 2441-2451. http://dx.doi.org/10.3233/JIFS-171695.

Ng, W. C., Teh, S. Y., Low, H. C., \& Teoh, P. C. (2017). The integration of FMEA with other problem solving tools: a review of enhancement opportunities. Journal of Physics: Conference Series, $890(1), 012139$. http://dx.doi.org/10.1088/1742-6596/890/1/012139.

Nguyen, H. (2016). A new interval-valued knowledge measure for interval-valued intuitionistic fuzzy sets and application in decision making. Expert Systems with Applications, 56, 143-155. http://dx.doi.org/10.1016/j.eswa.2016.03.007.

Rahmatin, N., Santoso, 1., Indriani, C., Rahayu, S., \& Widyaningtyas, S. (2018). Integration of the fuzzy failure mode and effect analysis (fuzzy FMEA) and the analytical network process (ANP) in marketing risk analysis and mitigation. International Journal of Technology, 9(4), 809-818. http://dx.doi.org/10.14716/ijtech.v9i4.2197.

Rezaee, M. J., Yousefi, S., Valipour, M., \& Dehdar, M. M. (2018). Risk analysis of sequential processes in food industry integrating multi-stage fuzzy cognitive map and process failure mode and effects analysis. Computers \& Industrial Engineering, 123, 325-337. http://dx.doi.org/10.1016/j.cie.2018.07.012.

Sutrisno, A., Moo, H., Lee, T., \& Hyon, J. (2013). Improvement strategy selection in FMEA: classification, review and new opportunity roadmaps. Operations and Supply Chain Management, 6(2), 54-63.

Singh, P. (2017). Distance and similarity measures for multiple-attribute decision making with dual hesitant fuzzy sets. Computational \& Applied Mathematics, 36(1), 111-126. http://dx.doi.org/10.1007/s40314-015-0219-2.

Sitnikov, C., Bocean, C. G., Berceanu, D., \& Pirvu, R. (2017). Risk management model from the perspective of implementing iso 9001: 2015 standard within financial services companies. Amfiteatru Economic, 19(11), 1017-1034.

Song, W., Ming, X., Wu, Z., \& Zhu, B. (2013). Failure modes and effects analysis using integrated weight-based fuzzy TOPSIS. International Journal of Computer Integrated Manufacturing, 26(12), 1172-1186. http://dx.doi.org/10.1080/0951192X.2013.785027.

Soyer, A., Asan, Ş. S., \& Asan, U. (2016). Failure mode and effects analysis using hesitant fuzzy sets. In Uncertainty Modelling in Knowledge Engineering and Decision Making: Proceedings of the 12th International Flins Conference (pp. 1089-1094). Singapore: World Scientific Publishing Company.

Tooranloo, H. S. (2016). A model for failure mode and effects analysis based on intuitionistic fuzzy approach. Applied Soft Computing, 49, 238-247. http://dx.doi.org/10.1016/j.asoc.2016.07.047.

Tooranloo, H. S., Ayatollah, A. S., \& Alboghobish, S. (2018). Evaluating knowledge management failure factors using intuitionistic fuzzy FMEA approach. Knowledge and Information Systems, 57, 183-205.

Torra, V. (2010). Hesitant fuzzy sets. International Journal of Intelligent Systems, 25(6), 529-539.

Tummala, R., \& Schoenherr, T. (2011). Assessing and managing risks using the supply chain risk management process (SCRMP). Supply Chain Management, 166), 474-483. http://dx.doi.org/10.1108/13598541111171165.

Valinejad, F., \& Rahmani, D. (2018). Sustainability risk management in the supply chain of telecommunication companies: a case study. Journal of Cleaner Production, 203, 53-67. http://dx.doi.org/10.1016/j.jclepro.2018.08.174.

Wang, H., Zhao, X., \& Wei, G. (2014). Dual hesitant fuzzy aggregation operators in multiple attribute decision making. Journal of Intelligent \& Fuzzy Systems, 26(5), 2281-2290. http://dx.doi.org/10.3233/IFS-130901.

Wang, L. E., Liu, H. C., \& Quan, M. Y. (2016). Evaluating the risk of failure modes with a hybrid MCDM model under interval-valued intuitionistic fuzzy environments. Computers \& Industrial Engineering, 102, 175-185. http://dx.doi.org/10.1016/j.cie.2016.11.003. 
Wang, W., Liu, X., Qin, Y., \& Fu, Y. (2018). A risk evaluation and prioritization method for FMEA with prospect theory and Choquet integral. Safety Science, 110, 152-163. http://dx.doi.org/10.1016/j.ssci.2018.08.009.

Wu, T., Blackhurst, J., \& Chidambaram, V. (2006). A model for inbound supply risk analysis. Computers in Industry, 574), $350-365$. http://dx.doi.org/10.1016/j.compind.2005.11.001.

Xu, K., Tang, L. C., Xie, M., Ho, S. L., \& Zhu, M. L. (2002). Fuzzy assessment of FMEA for engine systems. Reliability Engineering \& System Safety, 75(1), 17-29. http://dx.doi.org/10.1016/S0951-8320(01)00101-6.

Yazdi, M., Daneshvar, S., \& Setareh, H. (2017). An extension to Fuzzy Developed Failure Mode and Effects Analysis (FDFMEA) application for aircraft landing system. Safety Science, 98, 113-123. http://dx.doi.org/10.1016/j.ssci.2017.06.009.

Yu, D., Li, D. F., \& Merigo, J. M. (2016). Dual hesitant fuzzy group decision making method and its application to supplier selection. International Journal of Machine Learning and Cybernetics, 75), 819-831. http://dx.doi.org/10.1007/s13042-015-0400-3.

Zadeh, L. A. (1965). Fuzzy sets. Information and Control, 8(3), 338-353. http://dx.doi.org/10.1016/S0019-9958(65)90241-X.

Zeng, W., Xi, Y., Yin, Q., \& Guo, P. (2018, November). Weighted dual hesitant fuzzy sets and its application in group decision making. In 2018 14th International Conference on Computational Intelligence and Security (CIS) (pp. 77-82). New York: IEEE. http://dx.doi. org/10.1109/ClS2018.2018.00025.

Zhang, H., Dong, Y., Palomares-Carrascosa, 1., \& Zhou, H. (2019). Failure mode and effect analysis in a linguistic context: a consensusbased multiattribute group decision-making approach. IEEE Transactions on Reliability, 68(2), 566-582. http://dx.doi.org/10.1109/ TR.2018.2869787.

Zhang, H., Shu, L., Liao, S., \& Xiawu, C. (2017). Dual hesitant fuzzy rough set and its application. Soft Computing, 21(12), 3287-3305. http://dx.doi.org/10.1007/s00500-015-2008-7.

Zhang, J., Hegde, G. G., Shang, J., \& Qi, X. (2016). Evaluating emergency response solutions for sustainable community development by using fuzzy multi-criteria group decision making approaches: IVDHF-TOPSIS and IVDHF-VIKOR. Sustainability, 8(4), 291. http:// dx.doi.org/10.3390/su8040291.

Zhang, Z., \& Chu, X. (2011). Risk prioritization in failure mode and effects analysis under uncertainty. Expert Systems with Applications, 38(1), 206-214. http://dx.doi.org/10.1016/j.eswa.2010.06.046.

Zhu, B., Xu, Z., \& Xia, M. (2012). Dual hesitant fuzzy sets. Journal of Applied Mathematics, 2012, 879629.

Zhu, J., Wang, R., \& Li, Y. (2018). Failure mode and effects analysis considering consensus and preferences interdependence. Algorithms, 11(4), 34. http://dx.doi.org/10.3390/a 11040034.

Zolfaghari, S., \& Mousavi, S. M. (2018). Construction-project risk assessment by a new decision model based on De-Novo multiapproaches analysis and hesitant fuzzy sets under uncertainty. Journal of Intelligent \& Fuzzy Systems, 35(1), 639-649. http:// dx.doi.org/10.3233/JIFS-162013. 